\title{
A questão agrária no Brasil: história e historiografia
}

\section{The agrarian question in Brazil: history and historiography}

Flávia Paula Darossi*

MOTTA, Márcia Maria Menendes. O Rural à la gauche: campesinato e latifúndio nas interpretações de esquerda (1955-1996). Niterói: Editora da UFF, 2014. $278 \mathrm{p}$

*Mestranda do Programa de Pós-Graduação em História pela Universidade Federal de Santa Catarina e integrante do Laboratório de História Social do Trabalho e da Cultura (CFH-UFSC). Email: flavia.darossi@gmail.com 
Em O Rural à la gauche... a historiadora Márcia Motta apresenta um inédito e atualizado balanço historiográfico das principais interpretações e debates produzidos no Brasil durante a segunda metade do século XX acerca da história da questão agrária brasileira - especialmente no que se refere ao campesinato e ao latifúndio - e discute as veredas da constituição e profissionalização do campo científico da História Agrária no Rio de Janeiro a partir da década de 1970. A obra consiste na tese produzida pela autora para o cargo de professora titular na Universidade Federal Fluminense.

Motta é doutora em História Social do Trabalho pela Universidade Estadual de Campinas e professora no Departamento de História e no Programa de Pós-Graduação da Universidade Federal Fluminense desde 1992. Atualmente é uma das principais intelectuais que estudam e orientam pesquisas relacionadas à história da propriedade no Brasil do século XIX. É autora de Nas fronteiras do poder: conflito e direito à terra no Brasil do século XIX (1998), Direito à terra no Brasil: a gestação do conflito (1795-1824) (2009), Propriedades e disputas: fontes para a história do oitocentos (2011), e de uma série de outras publicações, artigos e livros organizados em parceria com outros historiadores, como o Dicionário da terra (2005), que reuniu importantes pesquisadores da questão agrária brasileira, e Formas de resistência camponesa: viabilidade e diversidade de conflitos ao longo da História (2008).

O ponto central de $O$ Rural à la gauche... reside na problematização das trajetórias intelectuais de cinco relevantes estudiosos do país reputadamente de esquerda, a saber, Nelson Werneck Sodré, Alberto Passos Guimarães, Caio Prado Jr., Maria Yedda L. Linhares e Ciro Flamarion S. Cardoso, com relação aos seus argumentos e abordagens teóricas sobre a história do Brasil. Essencialmente, isso implicava tratar da natureza e da formação dos modos de produção e estruturas sociais rurais do país. Direta ou indiretamente, estes autores se tornaram basilares para a construção do pensamento social brasileiro, assim como para os debates que fomentaram pesquisas posteriores a partir da instituição da linha de pesquisa da História Agrária (ou História Social da Agricultura). É preciso ressaltar que até meados do fim dos anos 1970, os estudos voltados à questão agrária no Brasil eram mais restritos à Economia e Sociologia Rural das Ciências Agrárias da USP e da Universidade Federal de Viçosa-MG. Neste sentido, o livro contempla claramente a história da historiografia brasileira e sua leitura revela-se indispensável aos estudantes e pesquisadores interessados pela história do Brasil.

Motta discorre sobre as principais obras dos referidos intelectuais e procura reconstruir as possibilidades de suas influências teóricas, não restritas a vertentes de esquerda, por meio da análise de citações, conceitos, notas de rodapé e interlocuções travadas nos campos das ciências sociais. Sabidamente inspirada pelos trabalhos de Antonio Gramsci e Edward P. Thompson, a autora incorpora à sua análise as condições históricas de produção e recepção dos 
textos selecionados, construindo como fio condutor da obra a ideia de uma história engajada politicamente, seja nos embates partidários dos anos $1950 \mathrm{e}$ 1960 , ou nas querelas acadêmicas das décadas posteriores. O leitor é levado a refletir sobre a importância do posicionamento político dos autores para a constituição de suas histórias, bem como para seus argumentos referentes às possibilidades de transformação social do país. Este é o ponto mais inovador do livro, que confere unidade e coesão aos diferentes capítulos que o integram.

A primeira parte apresenta o Campesinato e [o] latifúndio na perspectiva de um Brasil feudal. Disserta sobre a constituição do Partido Comunista Brasileiro e as múltiplas leituras do marxismo adaptadas à história do país, com base nas produções de dois intelectuais partidários. $\mathrm{O}$ primeiro capítulo apresenta a análise das principais obras de Nelson Werneck Sodré, quais sejam, Oeste: ensaio sobre a propriedade pastoril, de 1941, O que se deve ler para conhecer o Brasil, de 1943, Formação Histórica do Brasil, de 1944, e As razões da independência, de 1965 . O capítulo 02 discorre sobre a perspectiva de Alberto Passos Guimarães em seu principal estudo intitulado Quatro séculos de latifúndio, de 1963. Diferentemente, ambos os autores analisaram a formação e a condição atrasada do Brasil pautados na perspectiva da permanência, em pleno século XX, de resquícios feudais oriundos da colonização portuguesa. As principais características do atraso relacionadas pelos autores foram a manutenção das grandes propriedades e a permanente subjugação da população pobre do campo aos ditames coronelísticos e senhoriais. Motta infere que tanto o campesinato quanto o latifúndio brasileiro foram analisados pela lente oficial do Partido Comunista sem uma reflexão acurada sobre a aplicabilidade de seus principais conceitos. Mas a autora reconhece, por exemplo, que a nominação da tese feudal por Alberto Passos Guimarães deve antes ser compreendida enquanto instrumento político de defesa da urgência de uma reforma agrária no país. Tanto é que os diversos movimentos sociais rurais nos anos 1950 e 1960, como as Ligas Camponesas, e as experiências de sindicalismo de associações agrícolas de trabalhadores rurais sem terra, levaram alguns setores do PCB a revisar a natureza conceitual e a força política dos camponeses na história recente do Brasil.

Na segunda parte do livro, Motta expõe a crítica à tese feudal realizada pelo intelectual marxista Caio Prado Jr.. São analisadas as obras Formação do Brasil Contemporâneo, de 1942, História Econômica do Brasil, de 1945 citadas tanto por Sodré quanto por Passos Guimarães -, A Revolução brasileira, de 1966, e A questão agrária no Brasil, de 1979, além das publicações da Revista Brasiliense fundada pelo autor em 1955. O país era capitalista desde suas origens, visto que a colonização do Brasil se realizou na conjuntura do capitalismo mercantil. Para Motta, o modelo explicativo de Caio Prado, pautado nos condicionantes externos da colonização, não permite uma análise mais aprofundada sobre a consolidação do latifúndio enquanto processo histórico. 
Na terceira parte de $O$ Rural à la gauche..., a autora apresenta a criação da linha de pesquisa da História Agrária e destaca a importância das trajetórias de Maria Yedda Linhares e Ciro Cardoso para a consolidação do campo e a ampliação das pesquisas notadamente no âmbito da História acadêmica. Esta seção foi dividida em três capítulos. O primeiro trata das incursões de Linhares na pesquisa sobre o rural e analisa sua contribuição para a fundação do Centro de Pós-Graduação em Desenvolvimento Agrário da Fundação Getúlio Vargas em 1976, além de abordar os principais resultados de suas pesquisas na instituição, haja vista História do Abastecimento: uma problemática da questão (1530-1918) e História Política do Abastecimento (1918-1974), publicadas em 1979, e História da Agricultura: debates e controvérsias, de 1981, em coautoria com Francisco Carlos Teixeira da Silva. O principal objetivo de Linhares era discutir a questão agrária não mais como um entrave ao desenvolvimento capitalista - conforme sugeriam a tese feudal e Caio Prado Jr. -, mas sim como uma consequência desse mesmo processo histórico. Assim, o foco das pesquisas não deveria residir apenas no resultado da colonização brasileira, mas antes nas formas de distribuição e apropriação territorial e nos diferentes modos de produção associados à grande lavoura. Linhares e Teixeira da Silva, assim como Ciro Cardoso, dedicaram considerável atenção à questão metodológica com o levantamento de fontes para os estudos concernentes às temáticas da referida linha de pesquisa.

O segundo capítulo da terceira seção aborda as propostas de Ciro Cardoso e Jacob Gorender sobre o conceito de modo de produção escravista colonial. Gestado como contraponto ao modelo explicativo que refletia a colonização do Brasil notadamente nos moldes do capitalismo comercial, o conceito procurava evidenciar a relevância das contradições internas da sociedade colonial brasileira à formação econômica do país. Motta aprofunda a análise de Cardoso acerca das noções de brecha camponesa e protocampesinato escravo e participa a divergência conceitual com Gorender, para quem inexistia um setor camponês diverso da grande lavoura, na qual a brecha camponesa constituía-se unicamente pelo consentimento e interesse dos fazendeiros. Ademais, Motta discorre sobre o livro publicado por Cardoso em 1979, intitulado Agricultura, escravidão e capitalismo, e sua importância para as discussões conceituais e metodológicas que estimularam a iniciação da linha de pesquisa da História Agrária da UFF, principalmente em torno da história da agricultura, da história comparativa, e da história regional.

O último capítulo da seção investiga a recepção das perspectivas de Linhares e Cardoso nos debates sobre o rural e problematiza as causas do fato de que os livros dos aludidos autores desapareceram do mercado editorial brasileiro. Motta discute também a criação do Programa de Mestrado em História na UFF em 1971 e o papel de brasilianistas como Richard Graham, Stanley Hilton e Robert Slenes na formação das primeiras linhas de pesquisa, 
dentre as quais, a História Agrária em fins dos anos 1970.

$\mathrm{Na}$ quarta e conclusiva parte do livro, Os anos 1980 e os esforços de consolidação do campo científico, Motta destrincha a repercussão que o tema da questão agrária teve no Programa de Pós-Graduação em História da UFF, especialmente no que concerne às propostas de Linhares e Cardoso nas pesquisas discentes. São apresentados gráficos e tabelas das teses e dissertações defendidas no Programa e das orientações de trabalhos realizadas por Linhares, Ciro Cardoso, Graham, Ismênia Martins, João Fragoso, entre outros. Os estudos voltados à temática da História Agrária ganharam movimento em plena década de consagração da História Cultural e da revitalização da Nova História Política. Uma das possíveis razões elencadas foi o próprio contexto de abertura política e as propostas e debates sobre o Plano Nacional de Reforma Agrária e a Constituinte de 1988, juntamente com o acirramento dos conflitos e lutas pelo acesso democrático à terra no cenário nacional.

A defesa de Motta de uma História Social do campesinato que desnude os embates desiguais entre camponeses e fazendeiros na história do país nos leva a ponderar a atualidade do tema e os desafios dos futuros historiadores agrários. Dados obtidos em 2014 pelo INCRA baseados no Sistema Nacional de Cadastro Rural indicaram que as grandes propriedades do país somavam naquele até aquele ano cerca de 244 milhões de hectares, isto é, $130 \mathrm{mil}$ grandes imóveis que concentravam cerca de $47 \%$ de toda a área registrada pelo Sistema, ao passo que as 3 milhões de pequenas propriedades rurais totalizavam aproximadamente apenas $10 \%$ da área total registrada. ${ }^{1}$

Em conclusão, a publicação de $O$ Rural à la gauche... preenche um importante espaço para a reflexão historiográfica brasileira. Ao final do livro temos um complexo e construtivo balanço dos impasses da História sobre a questão agrária do Brasil. Minha única ressalva é a necessidade de uma nova revisão editorial.

1 Jornal O Globo, 09 de Jan. 2015, por Tatiana Farah. Concentração de terra cresce e latifúndios equivalem a quase três estados de Sergipe. Disponível em http://oglobo.globo.com/brasil/ concentracao-de-terra-cresce-latifundios-equivalem-quase-tres-estados-de-sergipe-15004053. Acessado em Nov. 2016.

Resenha recebida em novembro de 2016. Aceito em janeiro de 2016 